This item was submitted to Loughborough's Research Repository by the author.

Items in Figshare are protected by copyright, with all rights reserved, unless otherwise indicated.

\title{
Effect of flocculation on critical flux during crossflow microfiltration of bentonite suspensions
}

PLEASE CITE THE PUBLISHED VERSION

PUBLISHER

(c) Taylor \& Francis

VERSION

AM (Accepted Manuscript)

LICENCE

CC BY-NC-ND 4.0

\section{REPOSITORY RECORD}

Chellappah, Kuhan, E.S. Tarleton, and Richard J. Wakeman. 2009. "Effect of Flocculation on Critical Flux During Crossflow Microfiltration of Bentonite Suspensions". figshare. https://hdl.handle.net/2134/4761. 
This item was submitted to Loughborough's Institutional Repository (https://dspace.lboro.ac.uk/) by the author and is made available under the following Creative Commons Licence conditions.

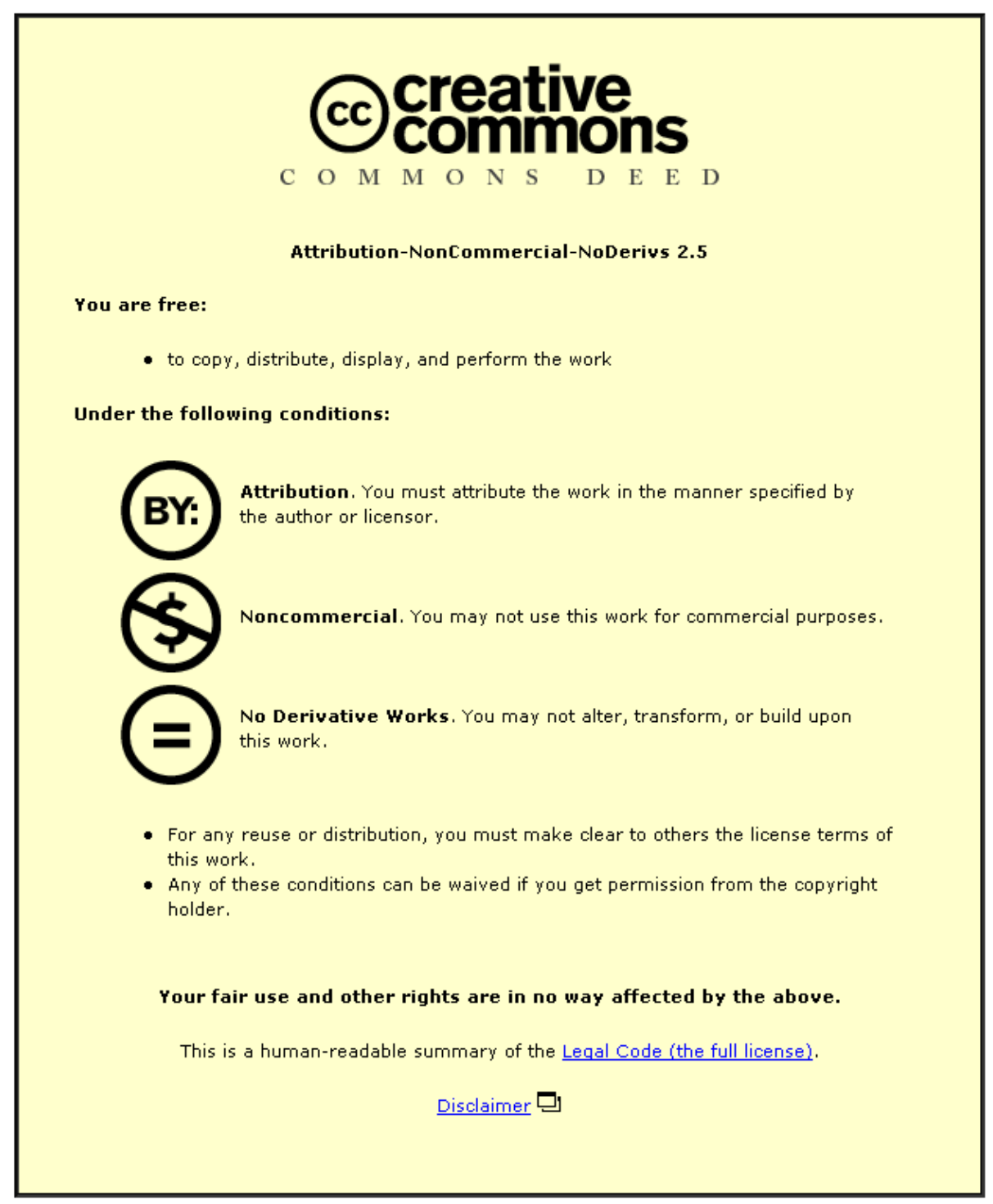

For the full text of this licence, please go to: http://creativecommons.org/licenses/by-nc-nd/2.5/ 


\title{
EFFECT OF FLOCCULATION ON CRITICAL FLUX DURING CROSSFLOW MICROFILTRATION OF BENTONITE SUSPENSIONS
}

\author{
K. Chellappah, E.S. Tarleton (e.s.tarleton@lboro.ac.uk) and R.J. Wakeman, \\ Department of Chemical Engineering, Loughborough University, Loughborough, Leicestershire \\ LE11 3TU, UK.
}

\begin{abstract}
The effectiveness of polymeric flocculant addition and hydrodynamics on increasing the critical permeation flux, $J_{\text {crit, }}$, during crossflow microfiltration of bentonite suspensions using a tubular ceramic membrane module was investigated. The investigation determined the effects of flocculant concentration on $J_{\text {crit }}$ at various crossflow velocities. The best filtration performance (highest $J_{\text {crit) }}$ ) was obtained at a flocculant dose of $500 \mathrm{mg} \mathrm{kg}^{-1}$ (mg of flocculant per kg of solids) and at a crossflow velocity of $1.71 \mathrm{~m} \mathrm{~s}^{-1}$. Particle size has been used as a parameter to fit the shear-induced hydrodynamic diffusion model to the experimental filtration data.
\end{abstract}

\section{INTRODUCTION}

Previous studies have shown that the permeate flux in a crossflow microfiltration can be significantly increased by flocculation (1-3). Mietton-Peuchot and Ben Aim (1) argued that crossflow filtration fouling is principally caused by fine particles and flocculation caused an increase in the particle size and hence the permeate flux, with the permeate flux being highest at the optimum flocculant concentration. Mietton-Peuchot and Ben Aim's argument that improved permeate flux with larger particles was substantiated by Tarleton and Wakeman (4) who found that reduced particle sizes in the feed resulted in lower overall permeate flux.

Various theoretical and experimental works have led to the conclusion that there is a critical permeation flux, $J_{\text {crit, }}$, below which there is no marked fouling and above which foulants start to deposit, altering the filtration performance (5-7). $J_{\text {crit }}$ can be determined by successive variations of trans-membrane pressure, TMP (7-9); this step by step technique has been used in the current work.

Previous works regarding flocculation to enhance microfiltration have mainly investigated the effects of flocculation on limiting or steady state flux values, not $J_{\text {crit. }}$ Over the last 10 years, numerous membrane filtration data have been obtained to investigate the concept of critical flux (9). Guo et al. (3) recently investigated the effect of flocculation on the performance of crossflow microfiltration in terms of $J_{\text {crit. }}$. However, only one flocculant concentration was investigated in their work, with no explanation given for the choice of concentration. In the current work, a range of flocculant concentrations are investigated in terms of the critical flux. Also the effects of varying crossflow velocity were not investigated by Guo et al. who only used one crossflow velocity $(0.15 \mathrm{~m}$ $\left.\mathrm{s}^{-1}\right)$.

Previous works have apparently either investigated the effects of flocculant concentration on the permeate flux at a given crossflow velocity, or the effects of crossflow velocity at a given flocculant concentration, not both. Also, previous works have generally assumed that the flocculant concentration that gives the best filtration performance (at a given crossflow velocity) is an optimum flocculant concentration. This work investigates the effects of flocculation on the critical flux during crossflow filtration of bentonite suspensions. Crossflow velocity and flocculant concentration affect the sizes of flocs in the feed stream, and so were the primary variables studied in this work. 


\section{THEORY}

\section{Critical Ratio and Critical Peclet Number}

Gésan-Guiziou and co-workers found a linear increase in $J_{\text {crit }}$ with wall shear stress in the filtration of skimmed milk (6) and latex particles (8), and attributed the gradients of these lines to a critical ratio, $J_{\text {crit }} / T_{w}$. Bacchin (10) theoretically explained the critical ratio linking $J_{c r i t}$ with hydrodynamics using a critical Peclet number. The Peclet number gives the relative importance between convection towards the membrane and diffusion away from it.

$$
P e_{c r i t}=\left(\frac{J}{k}\right)_{c r i t}=\left(\frac{J \delta}{D_{c}}\right)_{c r i t}
$$

where $k$ is the mass transfer coefficient, $D_{c}$ the diffusion coefficient and $\delta$ the boundary layer thickness. The approaches taken by Gésan-Guiziou and Bacchin are convergent as the wall shear stress and the boundary layer thickness can be related through the Fanning friction factor using traditional approaches such as the Chilton-Colburn analogies (10). This critical Peclet number (or critical ratio) is independent of hydrodynamic conditions and for a given membrane is only a function of suspension properties $(9,10)$.

The Peclet number combines in one expression both the effect of permeate flux and crossflow velocity (through the boundary layer thickness), and therefore represents the gradient of the $J_{\text {crit }}$ hydrodynamics relationship. This gradient should be constant for a given membrane providing the suspension properties remain constant since the critical Peclet number is a function of suspension properties. However, when dealing with flocculated suspensions, the assumption of constant suspension properties may not always hold as shearing tends to break up the flocs. As the suspension properties, and hence the critical Peclet number, are altered; non-linearity in the $J_{\text {crit }}$ hydrodynamics relationship should (theoretically) be evident.

\section{Determination of Shear Stress at the Membrane Wall and Critical Erosion Shear Stress}

The relation between wall shear stress, $T_{w}$, and the Fanning friction factor, $f$, and the approximation of Blasius in turbulent flow, assuming the membrane to be a smooth tubular element, enable $T_{w}$ to be calculated from the Reynolds number, Re, in the manner used by Gésan-Guiziou et al. $(6,8)$.

$$
\tau_{w}=0.04 \mathrm{Re}^{-0.25} \rho_{r} v^{2}
$$

where $v$ and $\rho_{r}$ are the crossflow velocity and retentate density respectively. Re is defined by $\rho v D / \mu$ where $D$ is the membrane tube hydraulic diameter, and $\rho$ and $\mu$ are the feed density and viscosity respectively. The diameter that remains open to flow has been assumed to remain at the initial value.

Using an analogy with a sedimentology model, a critical erosion shear stress was developed by Aubert et al. (11) which claimed to be a good approach to the analysis of interaction between particle deposits and the membrane. This critical erosion shear stress was defined as the shear stress that must be exceeded before surface erosion of the deposit takes place and applied to critical flux microfiltration by Gésan-Guiziou et al. (6). An efficient wall shear stress, $T_{\text {weff, }}$ and the critical erosion shear stress, $T_{w c 0}$, are related to the wall shear stress as described by equation (3),

$\tau_{\text {weff }}=\tau_{w}-\tau_{w c 0}$

Below the critical erosion shear stress, a critical flux does not exist. 


\section{Shear Induced Diffusion Model}

Davis and co-workers $(12,13)$ used an approach similar to the gel layer model for concentration polarization to postulate that permanent particle deposition on the membrane surface will take place beyond a certain distance from the feed entry point of the module, $x_{c r}$. As long as the effective viscosity of the suspension in the concentration polarised layer is low enough so that the existing shear flow is able to sweep the particles downstream, the membrane surface remains clean. The local concentration, and hence the local viscosity increases along the length of the membrane until a critical distance $x_{\text {crit }}$ from the membrane entrance, after which the shear flow is not able to sweep downstream all of the deposited particles, and permanent particle deposition on the membrane surface occurs at $x \geq x_{\text {crit }}$ (14). The model uses a shear induced hydrodynamic diffusivity rather than the Stokes-Einstein diffusivity.

If the main particle back transport mechanism is shear-induced diffusion, then $x_{c r}$ is given by (15):

$$
x_{c r}=1.0 \times 10^{-4} \frac{\tau_{w}^{3} a^{4}}{\phi_{b} \mu_{p}^{3} J_{w}^{3}}
$$

where $\phi_{b}$ is the volume fraction of particles in the bulk and a the particle radius. At the critical flux, $x_{c r}$ will be equal to the membrane length. This hypothesis means that at $J_{\text {crit }}, x_{\text {crit }}=X$, where $X$ is the length of the membrane. Substituting for $x_{\text {crit }}$ and solving for $J_{\text {crit }}$ gives:

$$
J_{\text {crit }}=\frac{\tau_{w}}{\mu_{p}}\left(\frac{1 \times 10^{-4} a^{4}}{\phi_{b} X}\right)^{1 / 3}
$$

Equation 4 is similar to those derived or used by other workers $(13,15,16)$.

\section{EXPERIMENTAL}

\section{Materials and Experimental Setup}

Suspension particle size distributions were measured using a Malvern Zetasizer $3000 \mathrm{HS}$; the particle size distributions of Wyoming bentonite before and after flocculation are shown in Figure 1. The zeta potentials of the bentonite particles were calculated from electrophoretic mobility using the Smoluchowski equation and were in the region of $-20 \pm 6 \mathrm{mV}$ at $\mathrm{pH}$ values ranging from 4 to 8 .

A high molecular weight, slightly anionic polyacrylamide flocculant, Magnafloc 10 was recommended by Ciba Specialty Chemicals and supplied in a granular powder form. The polymeric flocculants normally used in industry with clay mineral suspensions are polyacrylamide based. For high molecular weight polymers, bridging is usually the dominant mechanism of flocculation, not charge neutralisation, therefore it may not be necessary for the polymer to have a high charge density. Calcium chloride dihydrate, $\mathrm{CaCl}_{2} \cdot 2 \mathrm{H}_{2} \mathrm{O}$ (molecular mass 147.02), supplied by Fluka Chemika, was added to the suspensions to induce flocculation by salt bridging (17); previous work has also suggested better flocculation performance in the presence of a combination of metal ions and flocculants (18). Double distilled deionised water was used to make up the suspensions.

Four different $0.5 \mathrm{~g} \mathrm{~L}^{-1}$ bentonite suspensions in $0.1 \mathrm{M} \mathrm{CaCl}_{2}$ were filtered, with flocculant doses of $5000,2000,500$ and $200 \mathrm{mg} \mathrm{kg}^{-1}$ respectively. The $\mathrm{pH}$ of all the prepared suspensions was 6.8 $( \pm 0.2)$. The typical effects of flocculation on particle size are illustrated in Figure 1 . The $50 \%$ particle size before flocculation was approximately $1 \mu \mathrm{m}$. The $50 \%$ particle size after flocculation 
(as measured after a suspension has equilibrated during recirculation in the filtration rig and before filtration commences) is approximately $6 \mu \mathrm{m}$.

The rig used for the filtration tests is shown schematically in Figure 2. The microfiltration membrane was tubular ceramic (zirconia) as obtained from Fairey Industrial Ceramics Ltd and contained 7 tubular channels (each $4.7 \mathrm{~mm}$ in diameter), with an effective length of $0.55 \mathrm{~m}$. The average pore diameter was $0.2 \mu \mathrm{m}$ and the filtration area was $0.057 \mathrm{~m}^{2}$. The membrane was mounted within a stainless steel module in a flow circuit. Feeds of known, constant composition were pumped continuously through the module at specified crossflow velocities and transmembrane pressures. The temperature of the feed stream was regulated using a secondary circuit in which a plate type heat exchanger kept the feed temperature at $25 \pm 2^{\circ} \mathrm{C}$. This secondary circuit also provided most of the mixing effects, to keep particles in the suspension well dispersed.

The centrifugal pump in the secondary circuit tended to induce some floc breakage, representative of what may happen in industrial microfiltration plants (centrifugal pumps are the most widely used in the chemical industry). Besides floc breakage, re-flocculation may also occur in the feed tank and/or on the membrane surface. What is important, therefore, are floc strength and the hydrodynamic conditions on the membrane surface at the chosen crossflow velocities. In order to allow stabilisation of the floc size in the pumped flow circuit, the suspensions were re-circulated through the rig (primary and secondary circuits) for 30 minutes prior to the permeate valve being opened. The pump and valve settings (with the exception of the retentate and permeate isolation valves) were all preset to give the required crossflow velocity through the filter. The equilibration time was checked in preliminary experiments that monitored retentate particle size changes with time. The range of crossflow velocities chosen for investigation was 0.95 to $1.71 \mathrm{~m} \mathrm{~s}^{-1}\left( \pm 0.01 \mathrm{~m} \mathrm{~s}^{-}\right.$ $\left.{ }^{1}\right)$.

\section{Determination of Critical flux}

$J_{\text {crit }}$ was determined by successive increments/decrements of transmembrane pressure (using a step by step technique), similar to the technique described by Gésan-Guiziou et al. (8). The technique consists of systematic increases of TMP, each step had a 30 minute duration with a reading of permeate flux taken every 5 minutes ( 6 readings of $J$ at each TMP). The first unstable permeation flux was determined when the flux decreased with time at a given TMP step. After stepping up the pressure to a point beyond the critical TMP, the pressure was then stepped down again. The flux data corresponding to the upwards and downwards steps were plotted against TMP along with the clean water flux points obtained before an experiment with suspensions.

The critical flux was taken to be the point at which the $J=f(T M P)$ curve first deviates by $1 \%$ from the linear relationship of $J=f(T M P)$ given by clean water. The critical flux is defined in this way because the 'strong form' of critical flux $(5,9)$ was observed in the experiments. The critical flux determined by this method gave a value somewhere between the flux obtained during the last time independent step and the first time dependent step. An example of $J_{\text {crit }}$ determination is illustrated in Figures 3 and 4.

Some experiments were repeated to the point where the pressure step gave the first time dependent (unstable) permeation flux. These repeat experiments showed good reproducibility. For all experiments 8 pressure step ups and 4 pressure step downs were made, with 6 readings of permeate flux taken at each pressure step. For most experiments, between 3 to 5 pressure step ups were made below the critical flux and between 3 to 5 pressure steps were made above the critical flux. (For experiments with $200 \mathrm{mg} \mathrm{kg}^{-1}$ flocculant most pressure step ups were above the critical flux as the critical flux was very low.) For all experiments, at least 3 pressure step ups were made above the critical trans-membrane pressure. For all experiments, each of the 6 permeate flux readings at every pressure step below the critical flux were stable. The experimental error on critical flux is estimated to be less than $\pm 10 \%$. This error is based on the pressure step size 
during step ups, error in fit of the $J=f(T M P)$ curve to experimental data points, error in clean water flux, and on the experiments that were repeated.

\section{RESULTS AND DISCUSSION}

For the operating parameters studied, the step by step experiments showed two distinct zones, one below the critical flux and the other above. These two zones can be seen in Figure 3. Below the critical flux, the permeate flux remained constant throughout the duration of the step (30 min). Above the critical flux, the permeate flux showed instability in the course of the step, indicating permanent particle deposition.

Figure 5 shows the variation of $J_{\text {crit }}$ with crossflow velocity for suspensions at the chosen flocculant concentrations. The values of $J_{\text {crit }}$ were also plotted against flocculant concentration at the various crossflow velocities. This plot can be seen in Figure 6 where the suspension with flocculant dose of $500 \mathrm{mg} \mathrm{kg}^{-1}$ at a crossflow velocity of $1.71 \mathrm{~m} \mathrm{~s}^{-1}$ gave the highest $J_{\text {crit. }}$.

\section{Effects of Flocculant Concentration and Crossflow Velocity}

It is seen that an overall optimum flocculant concentration in terms of filtration performance is not obvious and is affected by the crossflow velocity used. Increasing the crossflow velocity may have complex effects, such as increasing collisions between particles on the filter surface (increasing the probability of re-flocculation), increasing back transport of particles from the filter surface, and causing excessive shearing that may give rise to floc breakage. At lower crossflow velocity, these effects are likely to be less significant, explaining why the effects of varying flocculant concentration on $J_{\text {crit }}$ are less pronounced at the crossflow velocities of $0.95 \mathrm{~m} \mathrm{~s}^{-1}$ and $1.14 \mathrm{~m} \mathrm{~s}^{-1}$.

When the suspension with $200 \mathrm{mg} \mathrm{kg}^{-1}$ flocculant in $0.1 \mathrm{M} \mathrm{CaCl}_{2}$ was filtered, lower $J_{\text {crit }}$ values were obtained. This agrees with the results obtained by Mietton-Peuchot and Ben Aim (1), who showed that a steep decrease in permeate flux ensued as the flocculant concentration was reduced below an optimum concentration. In their work, the reduction in permeate flux was less steep above the optimum flocculant concentration (compared to below it) which is in agreement with the results presented in the present work at the highest crossflow velocity of $1.71 \mathrm{~m} \mathrm{~s}^{-1}$; the 'optimum' flocculant concentration at this crossflow velocity was $500 \mathrm{mg} \mathrm{kg}^{-1}$. The increase of $J_{\text {crit }}$ with crossflow velocity for the suspension with $200 \mathrm{mg} \mathrm{kg}^{-1}$ flocculant was far less pronounced and deviated from linearity even at low crossflow velocities.

With the $200 \mathrm{mg} \mathrm{kg}^{-1}$ suspension, insufficient flocculant could have led to incomplete flocculation which in turn left behind sufficient fines to cause permanent pore blocking even at lower crossflow velocities. The effects of irreversible fouling by particulates is also indicated by noticeable hysteresis during the downwards pressure steps for this suspension at all crossflow velocities. By way of example, the hysteresis at a crossflow velocity of $1.71 \mathrm{~m} \mathrm{~s}^{-1}$ is shown in Figure 7.

Increasing the flocculant concentration from 200 to $500 \mathrm{mg} \mathrm{kg}^{-1}$ increased $J_{\text {crit }}$ by a factor between 2.5 and 5.5 for all crossflow velocities. This result is similar to that obtained by Guo et al. (3) who found pre-flocculation to increase the critical flux of synthetic wastewater by a factor of 3.8. Further increase in flocculant concentration (above $500 \mathrm{mg} \mathrm{kg}^{-1}$ ) brought about a slight reduction in $J_{\text {crit }}$ at the crossflow velocity of $1.71 \mathrm{~m} \mathrm{~s}^{-1}$ but did not seem to have as much effect at lower crossflow velocities. As previously mentioned, the unfavourable effects of crossflow velocity on these flocculated suspensions will be more pronounced at higher crossflow velocities. With more dense flocs, a higher crossflow velocity can be employed before suspension properties are significantly altered. This means that the influence of denser flocs will only be properly revealed at higher crossflow velocities. 
Above a flocculant dosage of $500 \mathrm{mg} \mathrm{kg}^{-1}$ it may be argued that the critical flux is more sensitive to variations in crossflow velocity than to any changes in flocculant dose. The use of a slightly anionic polyacrylamide to flocculate the negatively charged particles may have avoided the restabilisation of particles by excessive polymer adsorption driven by strong electrostatic attraction (19).

It is seen from Figure 5 that the general trend is a near linear increase in $J_{\text {crit }}$ with crossflow velocity at flocculant doses $>200 \mathrm{mg} \mathrm{kg}^{-1}$ and crossflow velocities not more than $1.52 \mathrm{~m} \mathrm{~s}^{-1}$. For all experiments, apart from those at $200 \mathrm{mg} \mathrm{kg}^{-1}$ flocculant, increasing the crossflow velocity from 0.95 $\mathrm{m} \mathrm{s}^{-1}$ to $1.71 \mathrm{~m} \mathrm{~s}^{-1}$ was found to increase the critical flux by a factor between 3 and 4.3 (Figure 5). This is similar to the results presented by Chiu and James (7) who found that increasing the crossflow velocity from 0.5 to $1.0 \mathrm{~m} \mathrm{~s}^{-1}$ increased the critical flux of their titanium dioxide suspensions by a factor of 4 . Similar gradients were obtained for the suspensions with 500,2000 and $5000 \mathrm{mg} \mathrm{kg}^{-1}$ flocculant at crossflow velocities not more than $1.52 \mathrm{~m} \mathrm{~s}^{-1}$.

Increasing the crossflow velocity from $1.52 \mathrm{~m} \mathrm{~s}^{-1}$ to $1.71 \mathrm{~m} \mathrm{~s}^{-1}$ did not have a significant effect on the critical flux of the suspensions with flocculant doses of 200,2000 and $5000 \mathrm{mg} \mathrm{kg}^{-1}$, probably because a balance had been established between the two effects of shearing, that is, the favourable effect of removing particles from the membrane surface and the unfavourable effect of breaking up previously formed flocs. The suspension with $500 \mathrm{mg} \mathrm{kg}^{-1}$ flocculant was the only suspension that continued to display an increase in $J_{\text {crit }}$ as the crossflow velocity was increased from $1.52 \mathrm{~m} \mathrm{~s}^{-1}$ to $1.71 \mathrm{~m} \mathrm{~s}^{-1}$. It is therefore likely that the flocs formed at this flocculant concentration $\left(500 \mathrm{mg} \mathrm{kg}^{-1}\right)$ were the only ones able to withstand the higher shearing (at $1.71 \mathrm{~m} \mathrm{~s}^{-}$ $\left.{ }^{1}\right)$ without excessive breakage.

\section{Model Fitting (Shear-Induced Diffusion)}

The shear induced diffusion model (SIDM) has been fitted to experimental data by varying the particle size, using it as a fitting parameter to give relatively smooth curves that 'best' fit the experimental data points (see Figure 8 ). Figure 8 shows that the critical erosion shear stress, $T_{w c 0}$, was about 2.3 Pa for all suspensions. The particle sizes used in the SIDM to fit the model to experimental data at the four crossflow velocities are plotted against crossflow velocity in Figure 9.

The 'fitted' particle sizes for the suspension with $200 \mathrm{mg} \mathrm{kg}^{-1}$ flocculant were lower than the others (Figure 9), approximately $0.38 \mu \mathrm{m}$ at the crossflow velocity of $0.95 \mathrm{~m} \mathrm{~s}^{-1}, 0.44 \mu \mathrm{m}$ at the crossflow velocities of 1.14 and $1.52 \mathrm{~m} \mathrm{~s}^{-1}$, and $0.36 \mu \mathrm{m}$ at the crossflow velocity of $1.71 \mathrm{~m} \mathrm{~s}^{-1}$, suggesting some floc breakage if the model is correct. The particles that initiated permanent particle deposition for the suspensions with flocculant doses of 500,2000 and $5000 \mathrm{mg} \mathrm{kg}^{-1}$ were found to be of similar sizes, with size increasing with crossflow velocity up to $1.52 \mathrm{~m} \mathrm{~s}^{-1}$. A maximum particle size is noted for the suspensions with flocculant doses of 2000 and $5000 \mathrm{mg} \mathrm{kg}^{-1}$. It is expected that if the crossflow velocity is increased even higher, eventually a maximum particle size will be reached for the suspension with $500 \mathrm{mg} \mathrm{kg}^{-1}$ flocculant as well.

\section{Effects of Particle Size}

The result illustrated in Figure 1 is in agreement with the statement made by Wickramasinghe et al. (20) that flocculated feed suspensions have a relatively wide particle size distribution compared to unflocculated feed streams. This can have a significant effect on the critical flux, for instance the SIDM predicts a critical flux dependence on particle diameter to the power of $4 / 3$. A number of other investigators $(15,21-25)$ have either shown or suggested that the presence of smaller particles often leads to lower permeate fluxes during microfiltration than may be expected based on the mean particle size.

Huisman et al. (15) hypothesised that the smallest particles in a polydisperse feed determine the $J_{\text {crit }}$ behaviour. They claimed that when they inserted particle sizes 'smaller' than their mean 
particle size into Equation (5), the same equation was used in their work; they found improved agreement between model predictions and experimental fluxes. However, they do not describe in detail what sizes or percentage size range gave the best fits. Figure 9 shows physical representations of particle sizes (at $J_{\text {crit }}$ ) in the bulk suspension within the membrane channel, given by the shear-induced diffusion model; these were in the $0.2-2 \%$ range of the feed suspension particle size distribution.

Therefore, above a certain particle size, it is important for the flocculation process to remove as many of the smaller particles as possible rather than to simply increase the mean particle size any further. The flocs formed also have to be of sufficient strength to withstand the shearing to which they are exposed. It is also expected that if the shear forces are increased even further, eventually a deviation from linearity will be observed for all suspensions used (even that with $500 \mathrm{mg} \mathrm{kg}^{-1}$ flocculant), as there will be a critical crossflow velocity above which the shearing will cause excessive breakage of the flocs. Above this crossflow velocity, the particle size distribution will be different, making it an essentially different suspension. Since the critical Peclet number is independent of hydrodynamic conditions but is a function of suspension properties $(9,10)$, the critical Peclet number will be altered, causing non-linearity in the $J_{c r i t}$ with $\tau_{w}$ relationship. This critical velocity will depend on the suspension and will be higher for strongly flocculated suspensions.

Any model that accurately describes the back transport mechanism and hence predicts $J_{\text {crit }}$ values can be expected to predict particles of this (lower) size range. Consequently, the physical representations of particle size given in Figure 9 can be considered to be reasonable, and the SIDM may be assumed to describe the physics involved during the microfiltration experiments carried out in this study. The model used here is also consistent with Bacchin's (10) realisation that if there is a critical Peclet number which is constant throughout the membrane (explaining the linear dependence with hydrodynamics), then there will be a distribution of local critical flux values along the membrane, with the lowest critical flux at the end of the membrane. However, it has to be pointed out that this is just an assumption, and as Wakeman (26) pointed out, a good fit of a model to experimental data does not imply that the physics described by the model is necessarily a correct interpretation of particle motions close to the membrane surface.

The SIDM has also been previously suggested to be the appropriate model for particles in this size range $(16,21,27)$. Any effects of re-flocculation, coupled with the fact that samples taken from the retentate stream are not representative of the particles that initiate particle deposition on the membrane surface, mean that the physical representations of particle size given by the SIDM cannot be conclusively confirmed by experiment.

\section{CONCLUSIONS}

The increase of $J_{\text {crit }}$ with crossflow velocity was most pronounced when the feed suspension was strongly flocculated and was least pronounced for a weakly flocculated suspension $\left(200 \mathrm{mg} \mathrm{kg}^{-1}\right)$. The shear-induced diffusion model was compared to experimental data when particle size was used as a fitting parameter. The 'fitted' particle sizes were in the lower ranges $(0.2-2 \%)$ of the measured feed particle size distributions, suggesting that these particles were responsible for the initial permanent particle deposition on the membrane surface at $J_{\text {crit. }}$ This is difficult to prove directly by experiment due to the inability to visualise and size particles lying on the membrane in situ in the filter.

\section{NOTATION}

A particle radius $(\mathrm{m})$

$D \quad$ hydraulic diameter of tube $(\mathrm{m})$ 


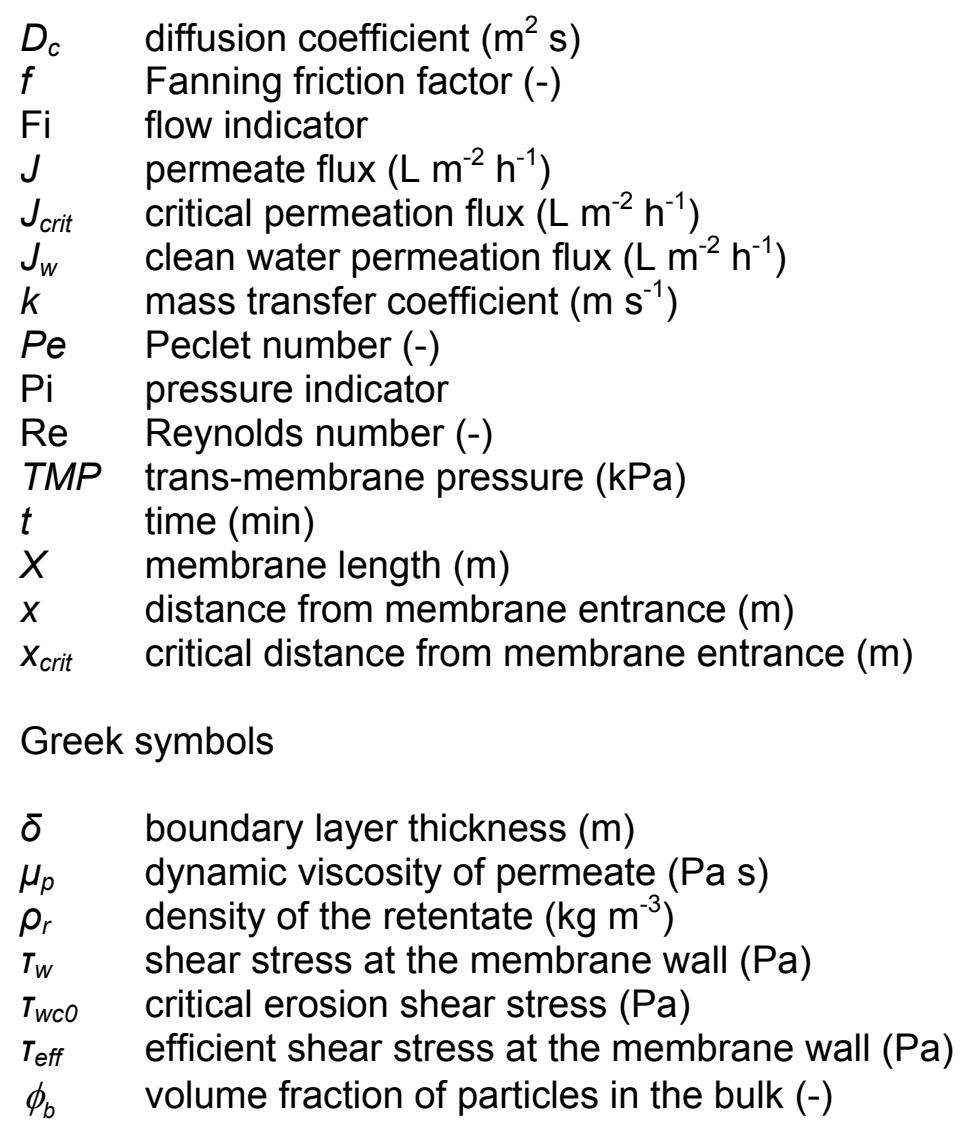

\section{REFERENCES}

1. Peuchot M.M. and Ben Aim R., 1992, Improvement of crossflow microfiltration performance with flocculation, J. Membr. Sci., 68, 241-248.

2. Kim J.S., Akeprathumchai S. and Wickramasinghe S.R., 2001, Flocculation to enhance microfiltration, J. Membr. Sci., 182, 161-172.

3. Guo W.S., Vigneswaran S. and Ngo H.H., 2005, Effect of flocculation and/or adsorption as pretreatment on the critical flux of crossflow microfiltration, Desalination, 172, 53-62.

4. Tarleton E.S. and Wakeman R.J., 1993, Understanding flux decline in crossflow microfiltration: Part 1 - Effects of particle and pore size, Trans IChemE, 71(A), 399-410.

5. Field R.W., Wu D., Howell J.A. and Gupta B.B., 1995, Critical flux concept for microfiltration fouling, J. Membr. Sci., 100, 259-272.

6. Gésan-Guiziou G., Boyaval E. and Daufin G., 1999, Critical stability conditions in crossflow microfiltration of skimmed milk: transition to irreversible deposition, J. Membr. Sci., 158, 211222.

7. Chiu T.Y. and James A.E., 2005, Critical flux determination of non-circular multi-channel ceramic membranes using $\mathrm{TiO}_{2}$ suspensions, J. Membr. Sci., 254, 295-301.

8. Gésan-Guiziou G., Wakeman R.J. and Daufin G., 2002, Stability of latex crossflow filtration: Cake properties and critical conditions of deposition, Chem. Eng. J., 85, 27-34. 
9. Bacchin P., Aimar P. and Field R.W., 2006, Critical and sustainable fluxes: Theory, experiments and applications, J. Membr. Sci., 281, 42-69.

10. Bacchin P., 2004, A possible link between critical and limiting flux for colloidal systems: consideration of critical deposit formation along a membrane, J. Membr. Sci., 228, 237-241.

11. Aubert M.-C., Elluard M.-P. and Barnier H., 1993, Shear stress induced erosion of filtration cake studied by a flat rotating disk method, J. Membr. Sci., 84, 229-240.

12. Davis R.H. and Leighton D.T., 1987, Shear induced transport of a particle layer along a porous wall, Chem. Eng. Sci., 42, 275-281.

13. Davis R.H. and Sherwood J.D., 1990, A similarity solution for steady-state crossflow microfiltration, Chem. Eng. Sci., 45, 3203-3209.

14. Romero C.A. and Davis R.H., 1990, Transient model of crossflow microfiltration, Chem. Eng. Sci., 45, 13-25.

15. Huisman I.H., Vellenga E., Trägårdh G. and Trägårdh C., 1999, The influence of the membrane zeta potential on the critical flux for crossflow microfiltration of particle suspensions, J. Membr. Sci., 156, 153-158.

16. Belfort G., Davis R.H. and Zydney A.L., 1994, The behaviour of suspensions and macromolecular solutions in crossflow microfiltration, J. Membr. Sci., 96, 1-58.

17. Moody G. and Norman P., 2005, in Solid/Liquid Separation: Scale-up of Industrial Equipment, Wakeman R.J. and Tarleton E.S. (Eds.), Elsevier, Oxford.

18. Mpofu P. and Addai-Mensah J. and Ralston J., 2003, Influence of hydrolysable metal ions on the interfacial chemistry, particle interactions, and dewatering behaviour of kaolinite dispersions, J. Colloid Interface Sci., 261, 349-359.

19. Clark A.Q., Herrington T.M. and Petzold J.C., 1990, The flocculation of kaolin suspensions with anionic polyacrylamides of varying molar mass and anionic character, Colloids Surf. A, 44, 247-261.

20. Wickramasinghe S.R., Han B., Akeprathumchai S., Chen V., Neal P. and Qian X., 2004, Improved permeate flux by flocculation of biological feeds: Comparison between theory and experiment, J. Membr. Sci., 242, 57-71.

21. Huisman I.H., Trägårdh G. and Trägårdh, C., 1999, Particle transport in crossflow microfiltration - II. Effects of particle-particle interactions, Chem. Eng. Sci., 54, 281-289.

22. Dharmappa H.B., Vernik J., Ben Aim R., Yamamoto K. and Vigneswaran S., 1992, A comprehensive model for crossflow filtration incorporating polydispersity of the influent, $J$. Membr. Sci., 65, 173-185.

23. Wickramasinghe S.R., 1999, Washing cryopreserved blood products using hollow fibres, Trans IChemE, 77(C), 287-292.

24. Tanaka T., Kamimura R., Fujiwara R. and Nakanishi K., 1994, Crossflow filtration of yeast broth cultivated in molasses, Biotechnol. Bioeng., 43, 1094-1101. 
25. Chellam S. and Wiesner M.R., 1998, Evaluation of crossflow filtration models based on shear induced diffusion and particle adhesion: complications induced by feed suspension polydispersity, J. Membr. Sci., 138, 83-97.

26. Wakeman R.J., 1994, Visualisation of cake formation in crossflow microfiltration, Trans IChemE, 72(A), 530-540.

27. Howell J.A., 1995, Sub-critical flux operation of microfiltration, J. Membr. Sci., 107, 165-171. 


\section{FIGURES}

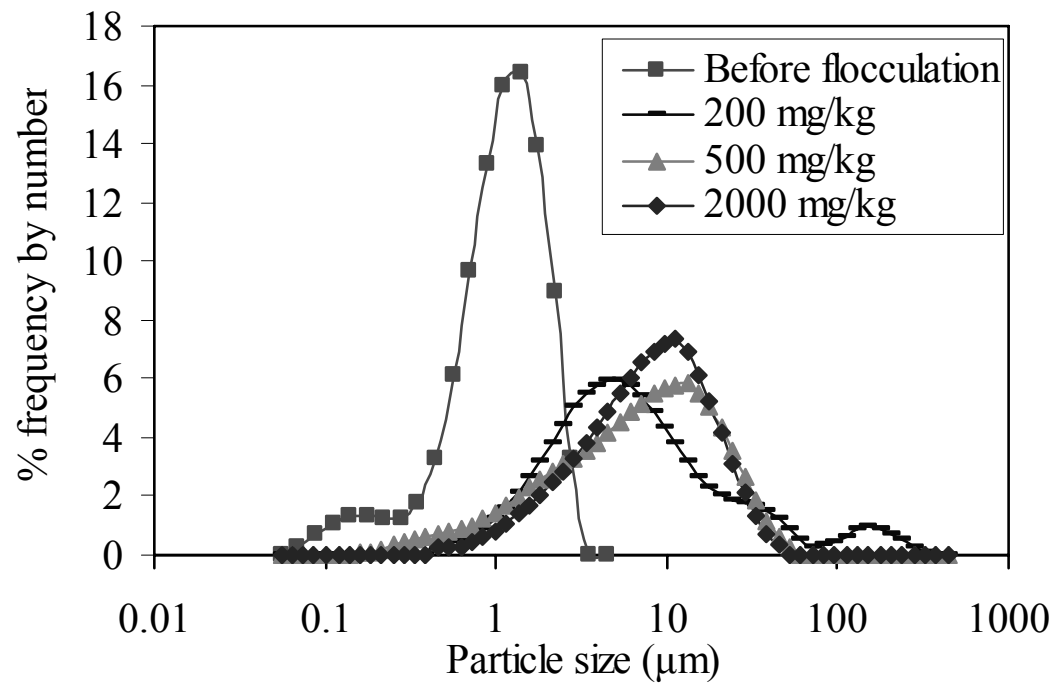

Figure 1: Typical effect of flocculation on the particle size distribution of the suspension. The effects of three flocculant dosages are shown here.

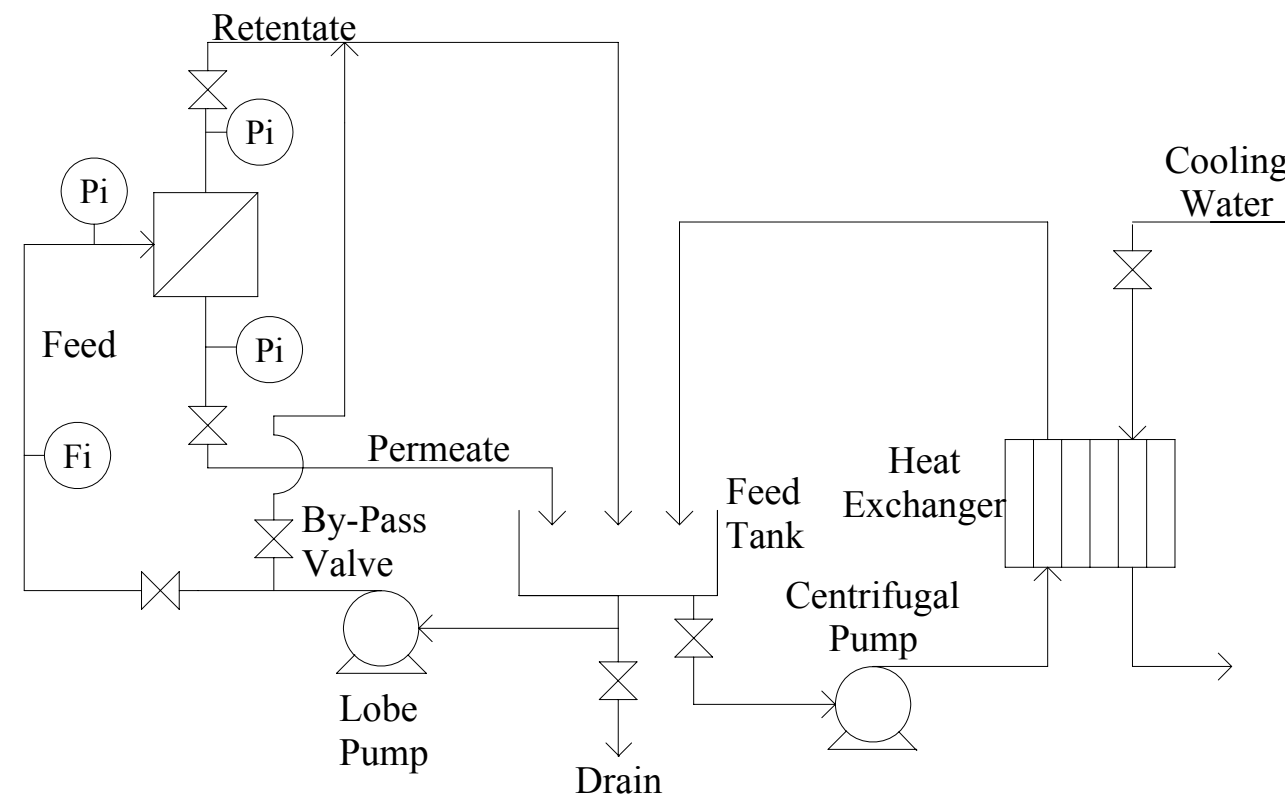

Figure 2: Schematic representation of the microfiltration flow circuit. Fi indicates flow indicator and $\mathrm{Pi}$ indicates pressure indicator. 


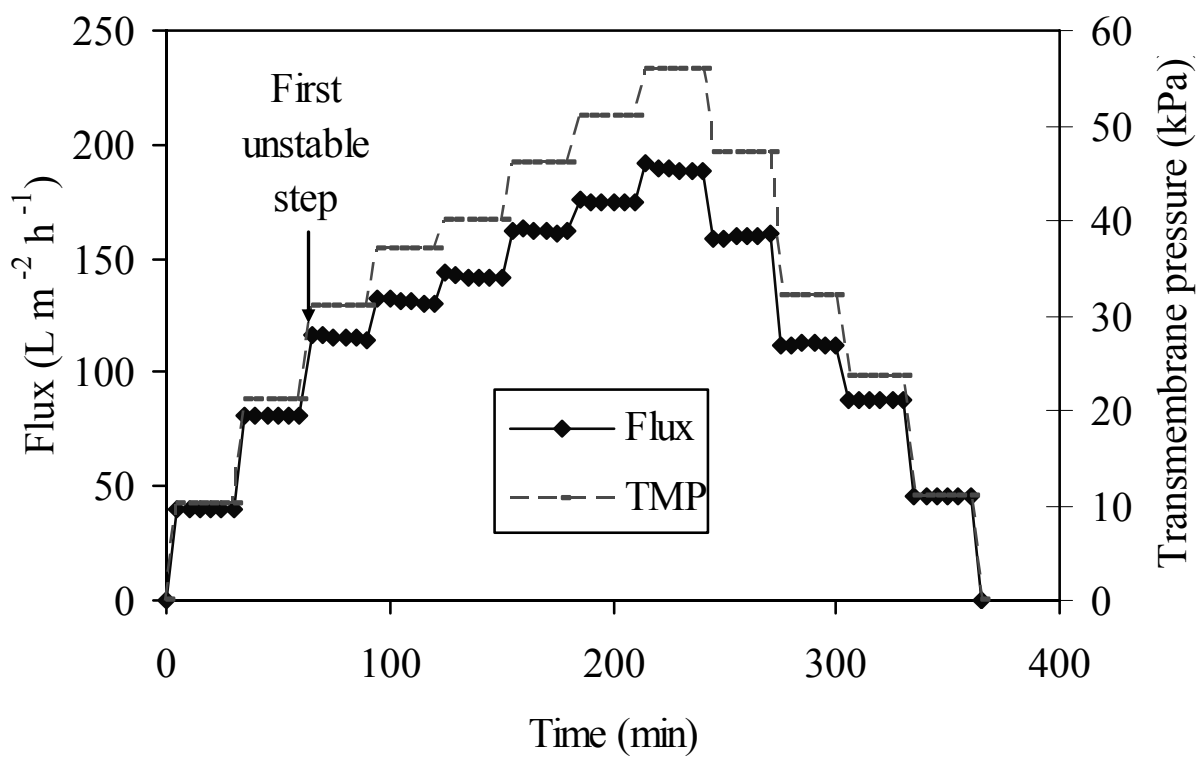

Figure 3: Step by step results at a crossflow velocity of $1.52 \mathrm{~m} \mathrm{~s}^{-1}$ for a flocculated $0.5 \mathrm{~g} \mathrm{~L}^{-1}$ bentonite suspension in $0.1 \mathrm{M} \mathrm{CaCl}_{2}$ with added flocculant at a concentration of $500 \mathrm{mg} \mathrm{kg}^{-1}$.

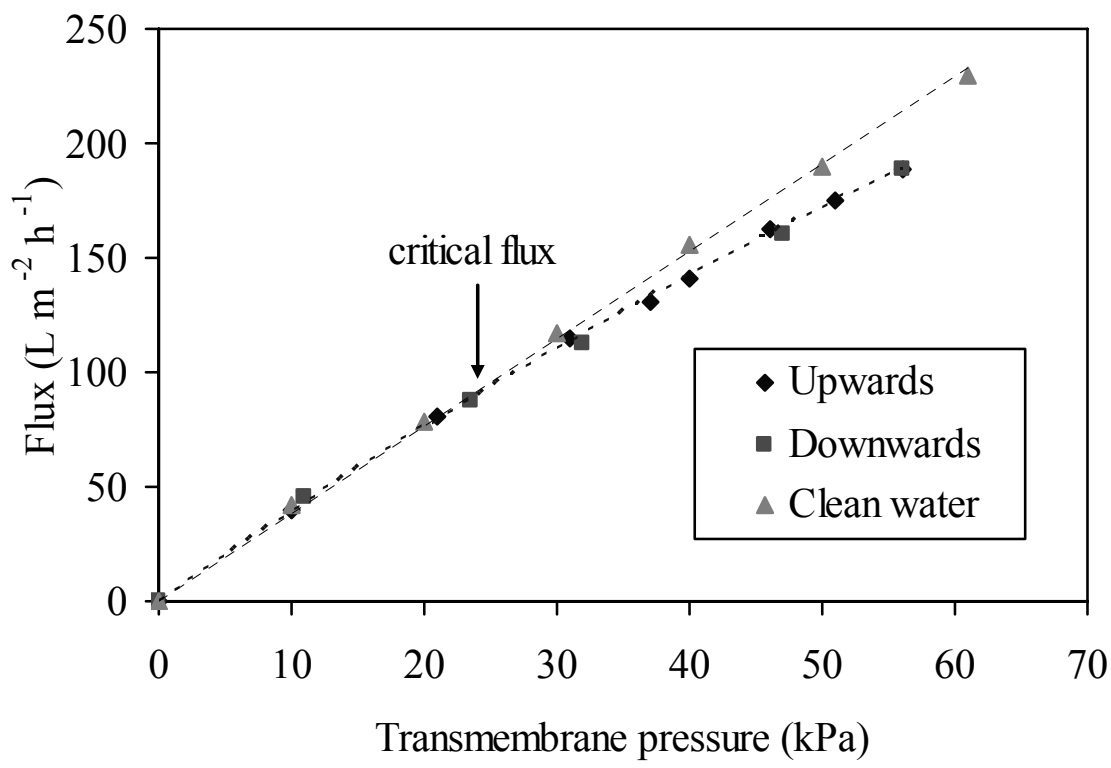

Figure 4: Flux versus trans-membrane pressure at a crossflow velocity of $1.52 \mathrm{~m} \mathrm{~s}^{-1}$ for flocculated $0.5 \mathrm{~g} \mathrm{~L}^{-1}$ bentonite suspensions in $0.1 \mathrm{M} \mathrm{CaCl}_{2}$ with added flocculant at a concentration of $500 \mathrm{mg}$ $\mathrm{kg}^{-1}$. Data are shown for both the upwards and downwards pressure steps, as well as the clean water flux trend obtained before the start of the experiment. 


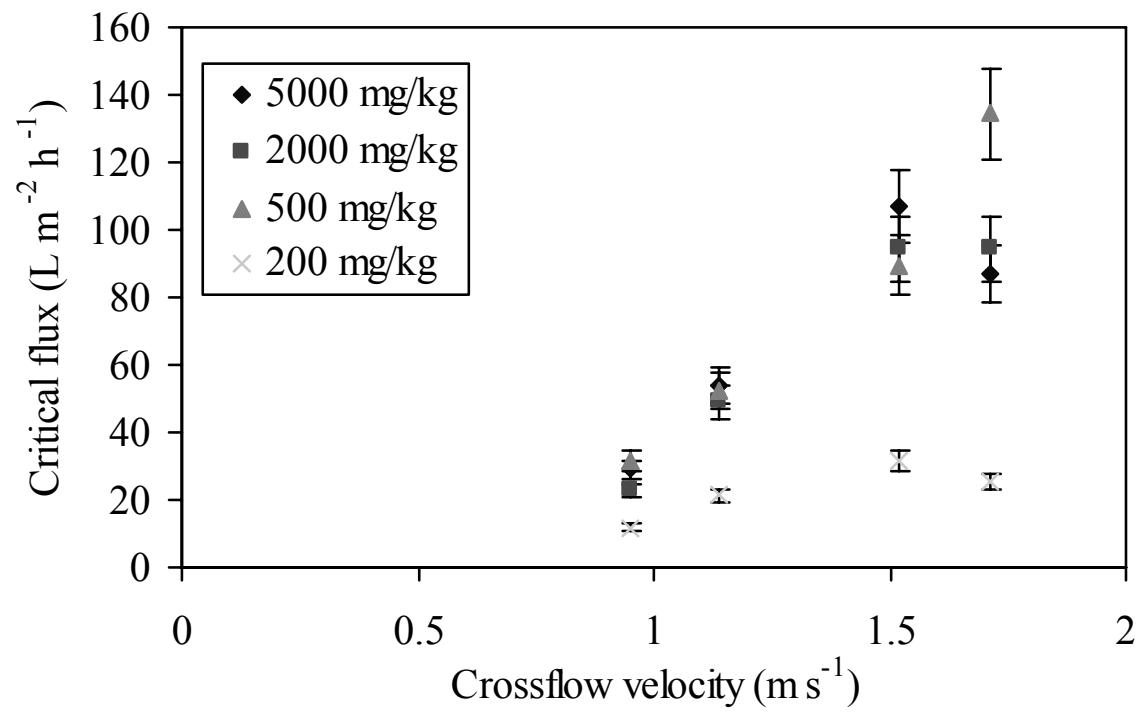

Figure 5: Variation of $J_{\text {crit }}$ with crossflow velocity for $0.5 \mathrm{~g} \mathrm{~L}^{-1}$ bentonite suspensions in $0.1 \mathrm{M} \mathrm{CaCl}_{2}$ with different flocculant concentrations.

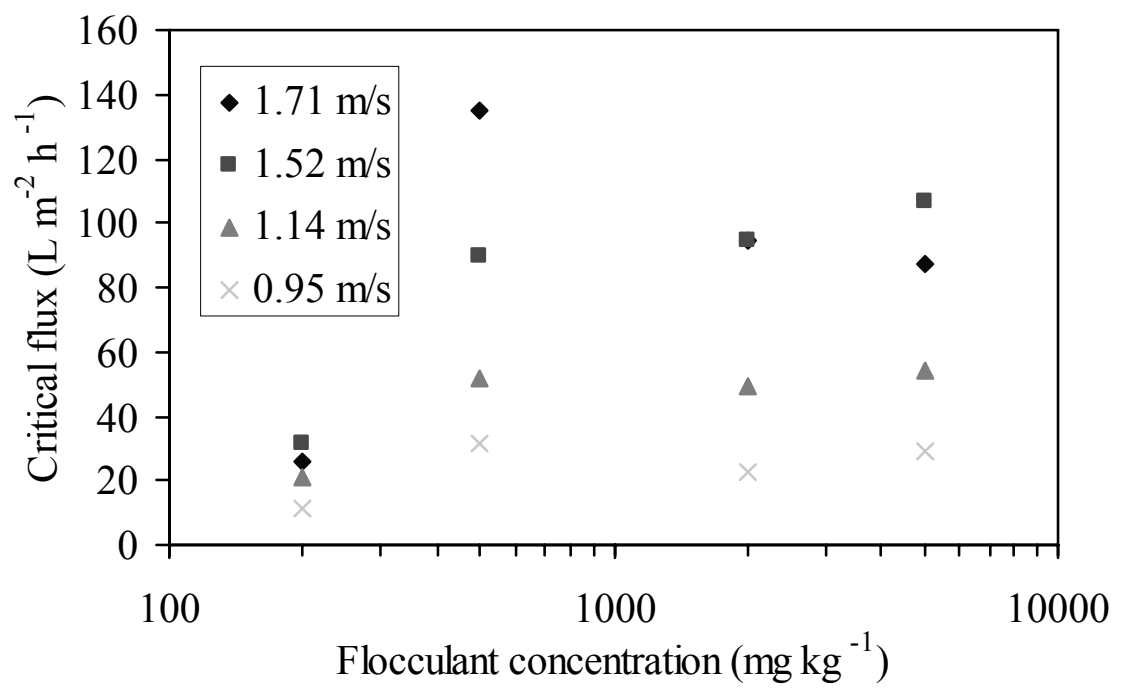

Figure 6: Variation of $J_{\text {crit }}$ with flocculant concentration at four different crossflow velocities. 


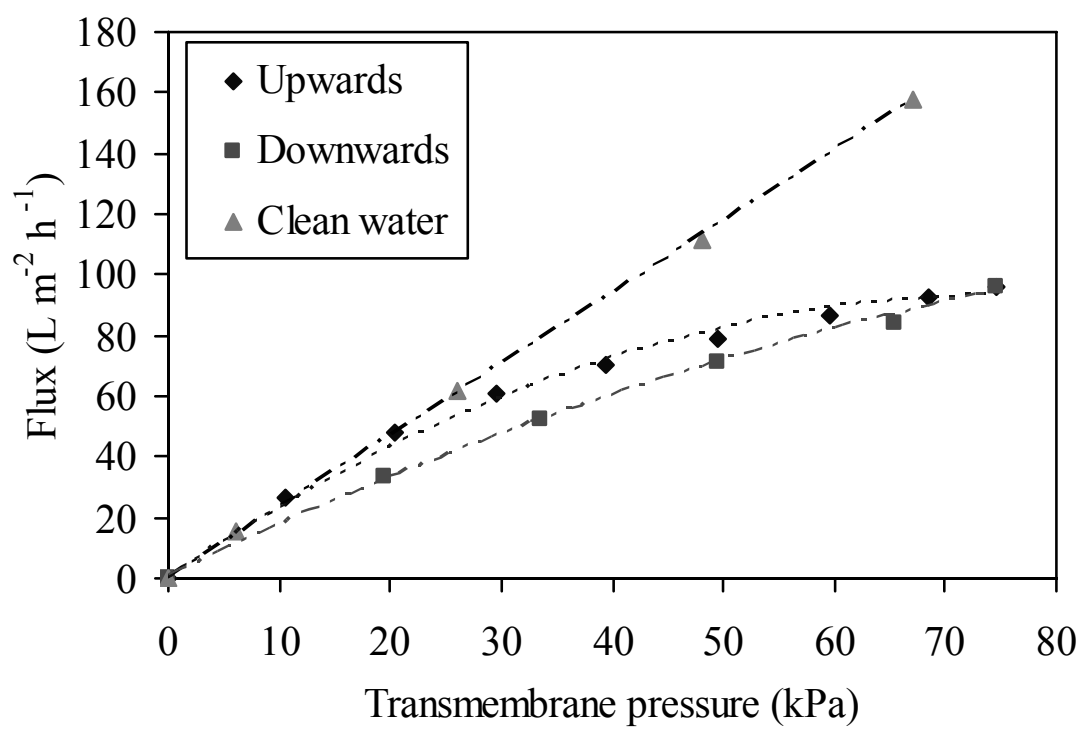

Figure 7: Flux performance with pressure step ups and then step downs for a $0.5 \mathrm{~g} \mathrm{~L}^{-1}$ bentonite suspension in $0.1 \mathrm{M} \mathrm{CaCl}_{2}$ with $200 \mathrm{mg} \mathrm{kg}^{-1}$ flocculant at a crossflow velocity of $1.71 \mathrm{~m} \mathrm{~s}^{-1}$. The clean water flux trend obtained before the start of the experiment is also shown.

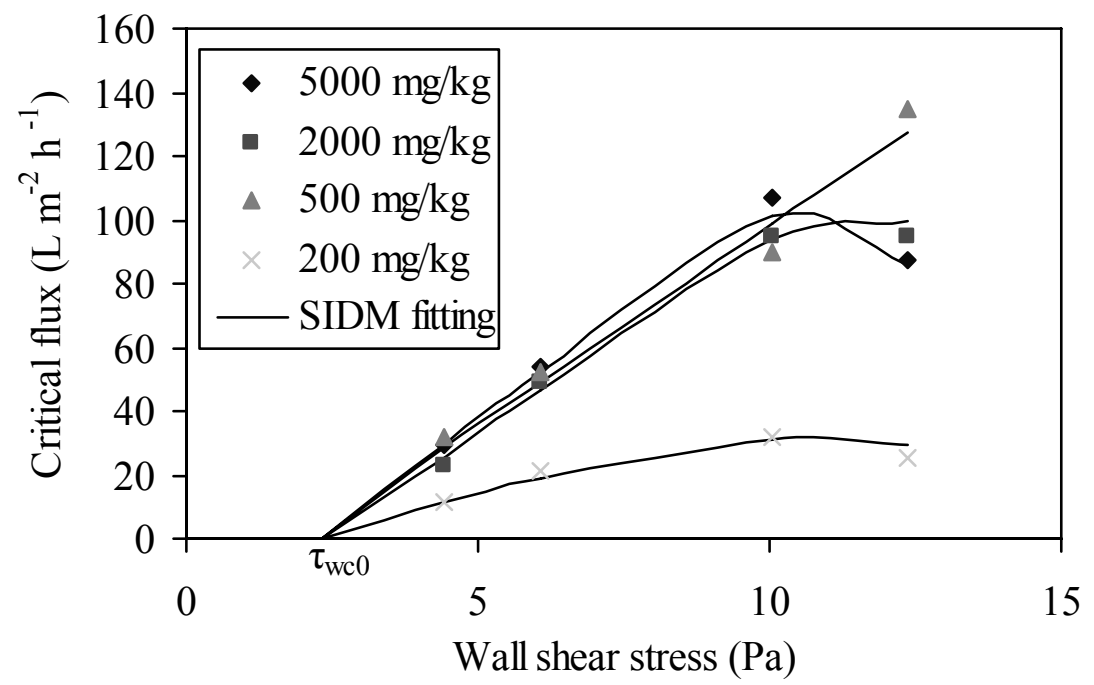

Figure 8: Shear-induced diffusion model (SIDM) fitted to experimental data obtained with $0.5 \mathrm{~g} \mathrm{~L}^{-1}$ suspensions in $0.1 \mathrm{M} \mathrm{CaCl}_{2}$ at four flocculant concentrations. The critical erosion shear stress, $T_{w c 0}$, is indicated. 


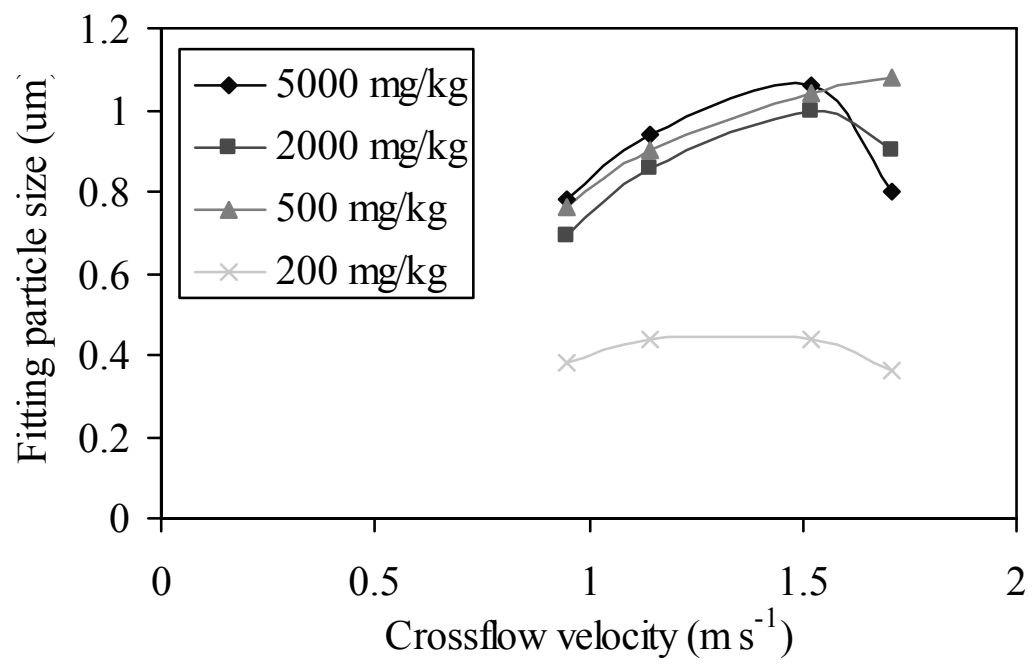

Figure 9: Particle sizes used in the shear-induced diffusion model at various crossflow velocities to fit the shear-induced diffusion model to experimental data. A physical representation of the particle sizes at $J_{\text {crit. }}$ 